\title{
Evolutionary thinking among biology students in a third world country
}

\author{
João C. F. Cardoso* (1) and Uiara C. Rezende
}

\begin{abstract}
Background: Evolutionary thinking is traditionally directly related to education and inversely to religiosity. Accordingly, biology students are naturally expected to be more prone to naturalist evolution due to their close contact with this theory and high scientific literacy. To test this, we performed a cross-national study surveying biology students' evolutionary opinions in Brazil, contrasting the proportions of creationism (Cr), divinely guided evolution (DGE) and naturalist evolution ( $\mathrm{NaE})$.

Results: We found that NaE comprised 44.4\%, DGE 43.3\%, and Cr 12.3\% of students' opinions. NaE was higher among postgraduate than undergraduate students. There were marked geographic differences, with NaE peaking in the most socioeconomically developed regions and $\mathrm{Cr}$ in the less. Opinions related to divine influence as a whole (Cr + DGE) became more likely as the score of students' institutions decreased (i.e. institutions with lower-quality standards).

Conclusions: Most biology students paradoxically do not have $\mathrm{NaE}$ as an explanation (55.6\%), a high proportion given their presumed contact with the theory. We demonstrate that socioeconomic and institution quality factors are apparently important in determining the evolutionary thinking patterns. NaE paucity among biology students may also be influenced by low scientific literacy and the extreme religiosity of the population, which incorporates divine influence in students' opinions long before they have any contact with evolutionary theory.
\end{abstract}

Keywords: Darwinism, Evolution, Creationism, Science education

\section{Background}

The evolution-creationism controversy has been a longstanding issue ever since the publication of Darwin's seminal work, On the Origin of Species, in 1859 (Moore et al. 2009). The opposed perspectives of creationism and evolution are associated with incompatible views on culture and religion as well as science (Miller et al. 2006; Moore et al. 2009; Scott 2009; Heddy and Nadelson 2012).

Despite being contentious subjects, creationism and evolution are not dichotomic in people's beliefs. As creationism displays several facets, there is a continuum between these two extremes, depending on the degree of science acceptance (Scott 2009). Among several viewpoints, for instance, classic creationism connotes that the creation event occurred relatively recently, approximately 10,000 years ago, and life has been created as it is today.

\footnotetext{
*Correspondence: jcfclg@gmail.com

Programa de Pós-Graduação em Ecologia e Conservação de Recursos

Naturais, Universidade Federal de Uberlândia, Uberlândia, MG, Brazil
}

Alternatively, various intermediate ideologies consider Earth to be ancient and the Creator to be responsible for the start and for changes along the process (sensu Scott 2009). However, scientific support is lacking for these and all other forms of divinely guided processes. On the other hand, naturalist evolutionary theory is one of the most robust and important in history, without being credibly falsified so far (Gould 2002; Mayr 2007; Scott 2009). It provides a materialist interpretation of issues such as the diversification, interrelatedness, and distribution of life on Earth. Evolutionary theory has been continuously supported by science, including natural selection, adaptation, selfish selection, mutations, genetic variation, gene flow, genetic drift, competition, fitness, extinction, and fossil record, offering a high explanatory and predictive power of natural processes (Gould 2002; Mayr 2007; Scott 2009).

Opinion surveys have been a valuable tool for investigating evolutionary thinking across different publics 
and localities. For instance, acceptance of evolution may be negatively related to social dysfunction indexes (Paul 2009) and income inequality (Rees 2009), and positively related to logical thinking skills (Lawson and Weser 1990; Lawson and Worsnop 1992). However, evolutionary thinking is most commonly positively related to education and scientific literacy (Miller et al. 2006; Rice et al. 2011; Sherkat 2011; Wiles and Alters 2011; Heddy and Nadelson 2012, 2013; Lloyd-Strovas and Bernal 2012) and negatively to religiosity (Lawson and Worsnop 1992; Sinclair et al. 1997; Larson and Witham 1998; Miller et al. 2006; Sherkat 2011; Heddy and Nadelson 2012, 2013; Clément 2015), suggesting that religiosity drives resistance to evolution (Coyne 2012).

However, evolution is expected to be predominant in some groups such as college biology students, due to their close contact with this theory and high level of education (Dias et al. 2012). Nevertheless, there is a lack of comparative studies with statistical analysis, sufficient sample sizes, and large geographic range, which hinders the understanding and decision-making of how and where to intervene (Nehm 2006; Lloyd-Strovas and Bernal 2012). In this sense, despite the assumptions of evolutionary predominance, more information is necessary, especially in less studied groups, such as postgraduate students. Finally, most researches concerning public opinions in evolution are concentrated in developed, rich countries (mainly in Europe and the USA), with few studies in the underdeveloped and emerging ones.

Brazil boasts the major research and graduate system in Latin America and the Caribbean (Andrade and Galembeck 2009). It is currently the 24th in global research, with areas that include biology such as "Earth \& Environmental Sciences" and "Life Sciences" together comprising approximately $1 / 4$ of the top research in the country (Nature Index 2016). Thus, it is important to understand students' perceptions on evolution, as they will be the future researchers and teachers, playing an important role in public opinion formation. Taking Brazil as a model system, we conducted a systematic survey on biology students' evolutionary opinions, contrasting creationism, divinely guided evolution and naturalist evolution (without divine intervention). Although Brazil has a large Catholic and, more recently, Evangelical, Pentecostalist and Adventist influences (IBGE 2012), we hypothesized that (1) biology students are more inclined to naturalist evolution. Despite Brazil's large territorial extension, we expected that (2) there are no regional effects on students' opinions once all of them are presumably in contact with evolutionary theory. Finally, we hypothesized that (3) those (supposedly few) deviations from naturalist evolution may be explained by the educational environment of students (i.e. institutions with lower-quality standards).

\section{Methods \\ Data collection}

We interviewed students attending national scientific events. We went to three conferences in distinct regions: ecology (2013; Porto Seguro city, Bahia state), botany (2013; Belo Horizonte, Minas Gerais), and zoology (2014; Porto Alegre, Rio Grande do Sul). Despite this convenience sampling may entail some biases (i.e. including mostly the more dedicated, advanced, or financially secured students), we adopted the strategy in order to reach a larger and geographically diversified public.

Students' evolutionary thinking was assessed through questionnaires. We adapted the procedure applied by the Gallup Organization, which has acquired USA citizens' opinions on creationism/evolution since 1982 (Gallup 2017). Interviewees were asked to answer the question: Which of the following assertions better expresses your opinion about the origin and development of human beings?: (1) God (or another divine force) created human beings already similar to what they look like nowadays approximately 10,000 years ago; (2) Human beings developed over the millions of years from other forms of life, with God (or another divine force) guiding the process; (3) Human beings developed over the millions of years from other forms of life, but God (or another divine force) had no part in the process.

This survey may lead to biases and distortions of the actual views, starting with the focus on human evolution, which may lead those interviewed to feel uncomfortable (Kampourakis and McCain 2016). In addition, misconceptions may be related to the further classifications of the three answer options. The main caveat is perhaps option 2 , which at the same time may assemble people prone to creationism and/or evolution. In fact, the most parsimonious conclusion is that answers related to option 1 establish a lower bound on the number of creationists in the sample while option 3 establish the opposite bound on the number of evolutionists. Even thought, we still used this methodology style because we intended to compare our results to previous studies on Brazilians common citizens and students (see "Discussion"). Here, we label options 1, 2 and 3 as "creationism" (Cr), "divinely guided evolution" (DGE) and "naturalist evolution" (NaE).

Since we were interested in the opinions of students currently enrolled in the biological sciences graduate course, we did not interview people who have completed their degrees (and stopped studying), students from other courses, or professionals. However, we also 
surveyed postgraduate students, but only those who graduated from the biological sciences course. We only considered stricto sensu (academic) postgraduates (students currently pursuing master's or doctoral degrees). Concerning undergraduate students, we gathered information about their age, graduation period, educational institution, and area of interest (ecology, botany, zoology, or other area). Among postgraduate students, we collected data about their age, area of interest, and educational institution, including the name of the postgraduate program. Based on data of specific educational institutions, students were situated in one of the five geographic macroregions of Brazil: North, Northeast, Center-West, Southeast, and South. For further analysis, we relocated students into the three geo-economic regions: Amazonia, Northeast, and Center-South (sensu Geiger 1964). In the mentioned order, these regions present a crescent degree of richness and development (Geiger 1964). In order to avoid geographical biases, we interviewed only people currently studying in the same geo-economic region in which they were born.

For each interviewee, we attributed a score using numeric indicators of quality provided by the Brazilian government for each educational institution. We used indicators that not only referred to the students' performance but also other elements of their educational environment, such as infrastructure and professors' quality. For the graduate level, we took CPC (Preliminary Concept of Course) scores from 2011 (INEP 2016a). We used the "continuous values," which range from zero to five. In the situation where institutions offer courses on two modalities ("Licenciatura" [teaching career] and "Bacharelado" [other assignments]), we extracted the average number. We did not attribute scores for courses that present "no concept" or for those that were not in the spreadsheet. Concerning postgraduates, we used the CAPES (Coordination for the Improvement of Higher Education Personnel) concept from 2013, in which values range from zero to seven (CAPES 2016). Since both the $\mathrm{CPC}$ and CAPES concepts are results from triennial evaluations, we selected those closest to the period in which the surveys were conducted.

\section{Statistical analysis}

The frequencies of opinions according to area (botany, ecology, and zoology), level (under and postgraduate), and macroregion (North, Northeast, Center-West, Southeast, and South) were compared in a multifactorial design by applying a log-linear model using the package MASS (Venables and Ripley 2002). Individuals who assigned "other area" (78 interviewees) in the area of interest were not analyzed regarding this factor. Besides the mentioned predictor variables, the whole model also comprised all possible interaction terms. After detecting effect for macroregions (see "Results"), we compared opinion frequencies according to geo-economic regions through a Chi squared test (5000 permutations simulated). Afterwards, we performed pairwise comparisons among the three regions, accepting a Bonferroni corrected $P<0.017$ as significant to reduce type I error (Cabin and Mitchell 2000).

We investigated which factors may be related to individuals' deviating opinions from $\mathrm{NaE}$ by submitting our continuous variables (age, graduation period, and institution score) to a mixed multinomial logistic regression using the package mlogit (Croissant 2012). In order to generate equivalence between graduate and postgraduate scores, we took the ratio value by dividing the obtained score by its maximum possible (graduate scores per five and postgraduate per seven). Students from institutions with no score were not analyzed regarding this factor. We checked for multicollinearity among the explanatory variables and considered it to be no problem in our data, as correlations among them were low (age vs. period: 0.37; age vs. score: -0.04 ; period vs. score: -0.03 ). Since effects of area, level, and macroregion were investigated previously with the log-linear model, these were treated as random effects. To test our specific hypothesis that divinely guided processes as a whole increase as institution quality decrease, we conducted a simple logistic regression grouping $\mathrm{Cr}$ and DGE.

In order to investigate possible institution score proportion differences, we fitted a two-way ANOVA with level and geo-economic region as fixed effects. Each institution was treated as a single replicate, regardless of the number of students belonging to it. Due to the unbalanced data for geo-economic region, we adjusted a "type II" sum of squares (Langsrud 2003) using the package car (Fox et al. 2016). Data distribution was examined by inspecting the homogeneity of the residual vs. fitted values plot (Zuur et al. 2009). Post hoc pairwise comparisons were performed using the Tukey's HSD test. All analyses were performed within $\mathrm{R}$ statistical environment version 3.4.0 (R Core Team 2017).

\section{Results}

We interviewed 1719 students from 123 graduate courses and other 123 postgraduate courses. Overall, the most common opinions were $\mathrm{NaE}(44.4 \%)$ and DGE (43.3\%), followed by $\mathrm{Cr}(12.3 \%)$. The frequency of opinions did not differ according to area of interest $\left(\chi^{2}=49.32, \mathrm{df}=48, P=0.42\right)$ or any possible interaction term (area"level"macroregion: $\chi^{2}=11.25, \mathrm{df}=16$, $P=0.79$; area"level: $X^{2}=13.42, \mathrm{df}=20, P=0.86$; area*macroregion: $\chi^{2}=24.50, \mathrm{df}=32, P=0.82$; level"macroregion: $\chi^{2}=29.64, \mathrm{df}=24, P=0.19$ ). 
However, we found that opinions differed according to student level $\left(x^{2}=76.28, \mathrm{df}=46, P<0.001\right)$. Postgraduate students (Cr: 7.7; DGE: 38.2; NaE: 54.1\%) were more prone to $\mathrm{NaE}$ at the expense of $\mathrm{Cr}$ and $\mathrm{DGE}$ when compared to undergraduate students $(\mathrm{Cr}: 14 \%$; DGE: 47\%; NaE: 39\%; Fig. 1). Ultimately, opinions frequency differed according to geographical macroregion $\left(\chi^{2}=132.80, \mathrm{df}=52, P=0.003\right.$; Fig. $\left.2 \mathrm{a}\right)$, in which $\mathrm{Cr}$ and

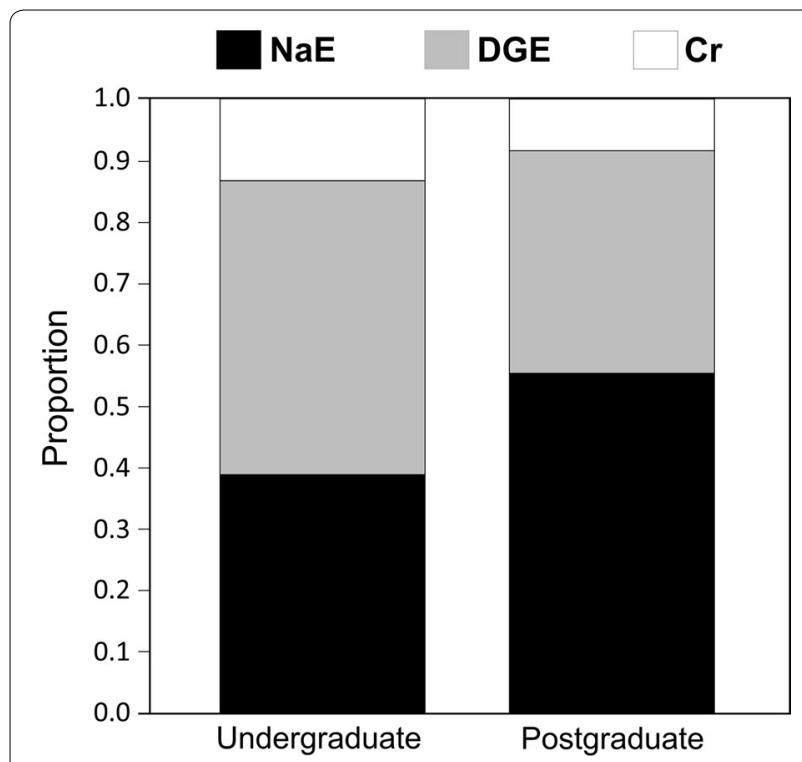

Fig. 1 Proportions of $\mathrm{NaE}, \mathrm{DGE}$, and $\mathrm{Cr}$ between undergraduate and postgraduate students
DGE increased northwards at the expense of $\mathrm{NaE}$, which reached its peak in the regions further south.

Further analyses confirm this, with a significant difference according to geo-economic regions $\left(\chi^{2}=104.74\right.$, $\mathrm{df}=4, P<0.001)$. Amazonia did not differ from the Northeast $\left(\chi^{2}=7.3, \mathrm{df}=2, P=0.027\right)$. On the other hand, the Center-South differed from both Amazônia $\left(\chi^{2}=42.41, \mathrm{df}=2, P<0.001\right)$ and the Northeast $\left(\chi^{2}=85\right.$, $\mathrm{df}=2, P<0.001$; Fig. 2b). Whereas DGE opinions remained similar in all three geo-economic regions, $\mathrm{NaE}$ was higher and $\mathrm{Cr}$ was lower in the Center-South.

Taking $\mathrm{NaE}$ as reference level, the multinomial logistic regression model was significant $\left(\chi^{2}=14.31, P=0.026\right)$. Age and period do not have any effect on the probability of choosing $\mathrm{Cr}$ or DGE (Table 1). On the other hand, as the institution score decreased, $\mathrm{Cr}$ became more likely (Fig. 3a). The same pattern was marginally significant for DGE. When $\mathrm{Cr}$ and DGE are taken together, the opinions related to divine influence as a whole decrease as the score increase $\left(\chi^{2}=8.37, z=-2.88\right.$, error $=0.38$, $P=0.003$; Fig. $3 b$ ).

The institution score proportion differed according to geo-economic region $(F=5.1, \mathrm{df}=2, P=0.007$ ). Amazonia (mean \pm SD: $0.55 \pm 0.14$ ) and the Northeast $(0.57 \pm 0.12)$ presented lower scores compared to the Center-South $(0.62 \pm 0.14)(P=0.03$ and 0.049 , respectively) and were not different from each other $(P=0.745$; Fig. 3c). The score proportion did not differ according to level $(F=0.09, \mathrm{df}=1, P=0.755)$ or the interaction term (geo-economic"level: $F=0.49, \mathrm{df}=2, P=0.61$ ).

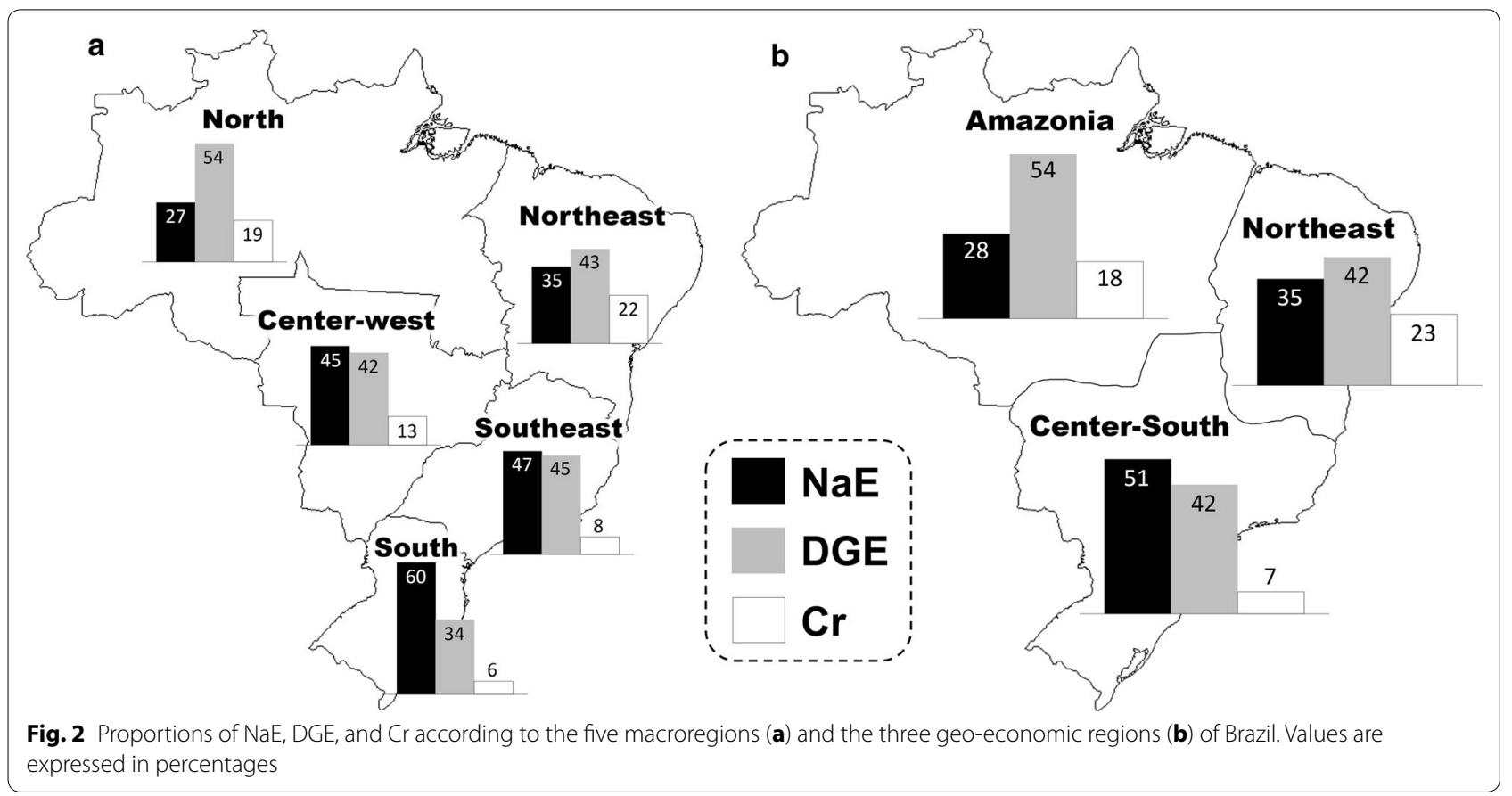


Table 1 Results of multinomial logistic regression for DGE and $\mathrm{Cr}$ taking NaE as reference level

\begin{tabular}{|c|c|c|c|c|c|c|}
\hline \multirow[t]{2}{*}{ Factors } & \multicolumn{3}{|l|}{ DGE } & \multicolumn{3}{|l|}{$\mathrm{Cr}$} \\
\hline & Error & $T$ & $P$ & Error & $T$ & $P$ \\
\hline Age & 0.025 & -1.060 & 0.288 & 0.032 & 0.321 & 0.747 \\
\hline Period & 0.038 & 0.169 & 0.865 & 0.052 & -1.887 & 0.059 \\
\hline Score & 0.607 & -1.765 & 0.077 & 0.805 & -2.937 & $0.003^{*}$ \\
\hline
\end{tabular}

*Significant results at 0.05 level
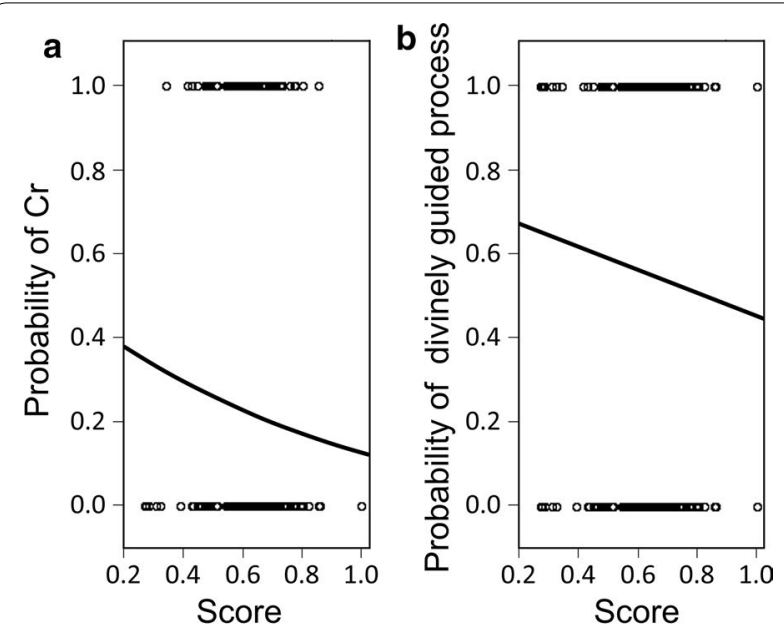

C

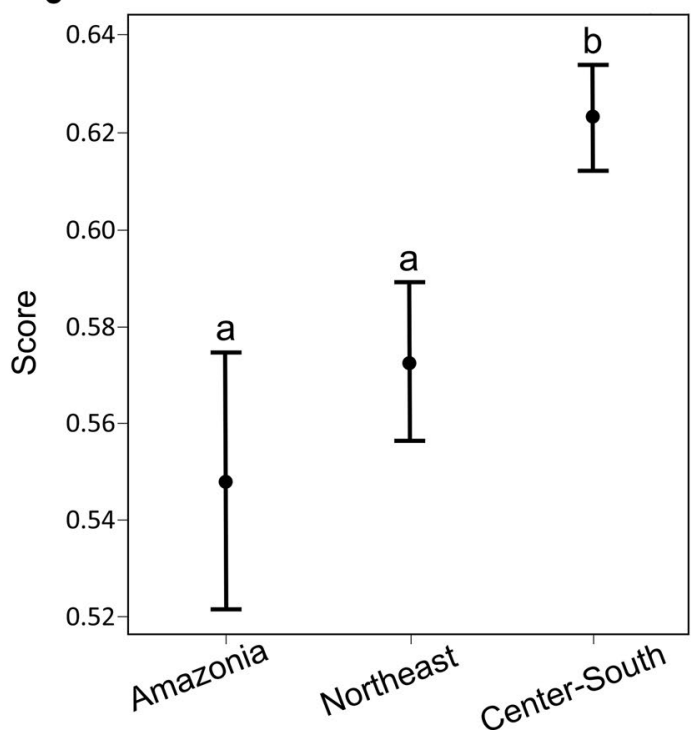

Fig. 3 a Probability of picking $\mathrm{Cr}$ (1) according to institution score proportion; results from multinomial logistic regression. b Probability of picking a divinely guided process ( $\mathrm{Cr}+\mathrm{DGE})(1)$ according to institution score proportion; results from simple logistic regression. Lines express predicted probability and dots the observed events. c Institution score proportion differences according to the three Brazilian geo-economic regions. Points display means and line segments $\mathrm{Cl}$ 95\%. Different letters represent significant differences at the 0.05 level

\section{Discussion}

Although biology students' acceptance of evolution may increase gradually through the years of college (Paz-yMiño and Espinosa 2009; Rocha et al. 2016), we did not find any changes, as in other studies (e.g. Bishop and Anderson 1990; Lawson and Worsnop 1992; Moore and Cotner 2009; Rice et al. 2011). This indicates that exposure to subjects with evolutionary tenor has no effect in students' opinions during the graduate course. However, the evolution proportion increased among postgraduates. Based on the lack of increase during the graduate continuum, we suggest that the postgraduate selective processes gather students whose quality is related to evolution (despite elevated DGE and Cr views even among postgraduates).

When compared to Brazilian citizens, biology students are more biased toward $\mathrm{NaE}$ and less to $\mathrm{Cr}$. The population in the country is only $8 \% \mathrm{NaE}$, followed by $59 \%$ DGE and 25\% Cr (Datafolha 2010). However, assuming that $\mathrm{Cr}$ and DGE are both forms of divinely guided processes, these together comprise more than half of biology students' opinions (55.6\%). Paradoxically, this indicates that $\mathrm{NaE}$ is not the predominant explanation in students' views. Nevertheless, Dias et al. (2012) interviewed students from the first graduation period from USP (University of São Paulo, Brazil), the largest university in South America, and found that the proportions of NaE, DGE, and $\mathrm{Cr}$ were $79.2,19.8$, and $1 \%$, respectively. The authors compared these findings with those from the veterinary school of the same institution (49.1, 45.6, and 5.3\%) and suggested that biology students are more prone to $\mathrm{NaE}$ even in early periods. Our results indicate that the national scenario is different from that of the USP firstperiod biology school. In fact, we found more $\mathrm{Cr}$ than Dias et al. (2012) did in the veterinary school, a course without contact with the theory of evolution. Why are the national parameters of biology students so dissimilar from those from USP (in biology and veterinary)? As evolutionary thinking is influenced by scientific literacy, USP probably has high-quality students already in the early periods. Our results concerning university score corroborate this, with students coming from low-scored 
institutions more likely to be inclined to $\mathrm{Cr}$ and divinely guided processes.

Based on our national parameters, we argue that the proportion of $\mathrm{NaE}$ among biology students is still low. Unfortunately, studies on evolutionary views are scarce in Brazil, and we still do not know which factors drive such a small proportion. For sure, problems concerning the quality of education in college and prior levels may influence evolution acceptance (Sinclair et al. 1997; Moore and Cotner 2009; Moore et al. 2011), but then again this information is lacking in the country. However, our unexpected marked regional differences may provide a clue, which is a fragile issue to discuss. It is known that 15 -year-old students from states within the less developed macroregions (North and Northeast, most of them within Amazonia and Northeast geo-economic regions) present lower performance, probably due to the socioeconomic factor (INEP 2016b). In addition, when entering college, these students have access to low-scored institutions, as pointed out in our results. Thus, lower socioeconomic levels and institution quality are apparently related to reduced $\mathrm{NaE}$ acceptance among biology students. In fact, the $\mathrm{NaE}$ proportion found in the whole country may be related to the current weak status of education. Accordingly, among the 65 countries evaluated by the PISA (Programme for International Student Assessment), Brazil ranks 59th in science literacy, with low performance also in other areas (PISA 2012).

Finally, as "creationism is a symptom of religion" (Coyne 2012), the high proportion of divinely guided processes found may be a by-product of the intense religiosity of Brazilians. Issues related to personal beliefs including life, death, and origins may lead college students to respond more emotionally than rationally (Lawson and Weser 1990), and religion plays a key role in determining such beliefs (Sinclair et al. 1997; Alters and Nelson 2002). In general, people acquire their faith before having contact with evolution (Coyne 2012), most of them during childhood, being subjected to childhood indoctrination (sensu Dawkins 2006). Hence, even a graduate course deeply rooted in $\mathrm{NaE}$ may have no effect on extremely religious people. In the last national demographic census, 91.9\% of Brazilians declared to have a religion (with no marked differences among the five macroregions) (IBGE 2012). Since adults traditionally transfer their values to the young (IBGE 2012), a considerable number of children grow up with a religion already determined. As a proxy of childhood indoctrination, for instance, $92.2 \%$ of children between 5 and 9 years old declare themselves to have a religion (IBGE 2012), long before having contact with any evolutionary theory.

\section{Conclusions}

In this study, we found that the majority of biology students paradoxically do not have $\mathrm{NaE}$ as an explanation, despite having presumed contact with the theory. In Brazil, opinions towards $\mathrm{NaE}$ were determined by socioeconomic and institution quality factors. We suggest that other attributes may also be important, such as low scientific literacy and the extreme religiosity of the population.

It is known that teachers naturally transmit their personal views to students (Carlsen 1991; Rocha et al. 2016). In addition, less economically developed countries present teachers with higher creationist conceptions (Clément 2015). Once biology students become researchers and teachers, our concern is that this $\mathrm{NaE}$ paucity may have a negative effect in classrooms in the long term, preventing the subject from being properly taught. Evolution is a fundamental issue in scientific literacy, providing groundwork for understanding a wide variety of topics in biology and other fields. Our study points out that evolution education needs to be reviewed in Brazil, and probably in other underdeveloped and emerging countries. We need a curricular/pedagogical reform aiming to fortify education on this important issue, from basic education to college.

\section{Abbreviations \\ CAPES: Coordenação de Aperfeiçoamento de Pessoal de Nível Superior (Coordination for the Improvement of Higher Education Personnel); CPC \\ Conceito Preliminar de Curso (Preliminary Concept of Course); Cr: creationism; DGE: divinely guided evolution; NaE: naturalist evolution; PISA: Programme for International Student Assessment; USP: Universidade de São Paulo (University of São Paulo).}

\section{Authors' contributions}

JCFC and UCR designed the study, collected and analyzed the data. JCFC wrote the first draft of the manuscript. Both authors contributed to the following versions. Both authors read and approved the final manuscript.

\section{Acknowledgements}

We are grateful to Lucas C. Oliveira, Eugenie C. Scott and Joshua Rosenau for their help and encouragement.

\section{Competing interests}

The authors declare that they have no competing interests.

Availability of data and materials

Data are available at: https://figshare.com/s/8fe520a946ae1acd9d52.

\section{Ethics approval and consent to participate}

This research was approved by the ethics committee of the Federal University of Uberlândia. All participants were invited to participate of the study and signed a term informing their consent.

Funding

The authors declare that they did not have any funding.

\section{Publisher's Note}

Springer Nature remains neutral with regard to jurisdictional claims in published maps and institutional affiliations. 
Received: 26 April 2017 Accepted: 15 September 2017

Published online: 03 October 2017

\section{References}

Alters BJ, Nelson CE. Teaching evolution in higher education. Evolution. 2002;56(10):1891-901.

Andrade JB, Galembeck F. Qualis: quo vadis? Quim Nova. 2009;32(1):5.

Bishop BA, Anderson CW. Student conceptions of natural selection and its role in evolution. J Res Sci Teach. 1990;27:415-27.

Cabin RJ, Mitchell RJ. To bonferroni or not to bonferroni: when and how are the questions. Bull Ecol Soc Am. 2000:81(3):246-8.

CAPES - Coordenação de Aperfeiçoamento de Pessoal de Nível Superior. 2016. http://www.avaliacaotrienal2013.capes.gov.br/home-page/noticias-publicas/resultadofinaldaavaliacaotrienal2013-aposreconsideracao. Accessed 16 Jan 2016

Carlsen WS. Effects of new biology teachers' subject-matter knowledge on curricular planning. Sci Educ. 1991;75(6):631-47.

Clément P. Creationism, science and religion: a survey of teachers' conceptions in 30 countries. Proc Soc Behav Sci. 2015;167:279-87.

Coyne JA. Science, religion, and society: the problem of evolution in America. Evolution. 2012;66(8):2654-63.

Croissant Y. Estimation of multinomial logit models in R: the mlogit package. 2012. http://cran.r-project.org/web/packages/mlogit/vignettes/mlogit. pdf. Accessed 29 Mar 2016.

Datafolha Instituto de Pesquisas. 59\% acreditam na evolução entre as espécies, sob o comando de Deus. 2010. http//www.datafolha.folha.uol.com br/opiniaopublica/2010/04/1223573-59-acreditam-na-evolucao-entreas-especies-sob-o-comando-de-deus.shtml. Accessed 16 Feb 2017.

Dawkins R. The God delusion. London: Bantam Press; 2006

Dias IA, Willemart RH, Marques AC. Does evolution matter?: a case study in Brazil of the effects of an evolutionary-thinking academic atmosphere in postgraduate students' belief in God/religious belief. An Acad Bras Cienc. 2012;84(2):551-4.

Fox J, Weisberg S, Adler D, Bates D, Baud-Bovy G, Ellison S, Firth D, Friendly M, Gorjanc G, Graves S, et al. Package 'car'. 2016. http://cran.r-project.org/ web/packages/car/car.pdf. Accessed 10 Feb 2017.

Gallup. In US, Belief in Creationist View of Humans at New Low. 2017. http:// www.gallup.com/poll/210956/belief-creationist-view-humans-new-low. aspx. Accessed 17 Jun 2017.

Geiger PP. Organização regional do Brasil. R Geogr. 1964;61:25-57.

Gould SJ. The structure of evolutionary theory. Harvard: Harvard University Press; 2002.

Heddy BC, Nadelson LS. A global perspective of the variables associated with acceptance of evolution. Evo Edu Outreach. 2012;5(3):412-8.

Heddy BC, Nadelson LS. The variables related to public acceptance of evolution in the United States. Evo Edu Outreach. 2013;6(1):3.

IBGE_-Instituto Brasileiro de Geografia e Estatística. Censo Demográfico 2010: Características gerais da população, religião e pessoas com deficiência. 2012. http://www.biblioteca.ibge.gov.br/visualizacao/periodicos/94/ cd_2010_religiao_deficiencia.pdf. Accessed 23 Mar 2016.

INEP_-Instituto Nacional de Estudos e Pesquisas Educacionais. 2016a. http:// portal.inep.gov.br/educacao-superior/indicadores/cpc. Accessed 12 Jan 2016.

INEP_Instituto Nacional de Estudos e Pesquisas Educacionais. 2016b. http:// www.download.inep.gov.br/acoes internacionais/pisa/resultados/2014/ relatorio_nacional_pisa_2012_resultados_brasileiros.pdf. Accessed 23 Mar 2016.

Kampourakis K, McCain K. Believe in or about Evolution? Bioscience. 2016:66(3):187-8
Langsrud $\varnothing$. ANOVA for unbalanced data: use Type II instead of Type III sums of squares. Stat Comput. 2003;13(2):163-7.

Larson EJ, Witham L. Leading scientists still reject God. Nature. 1998;394:313.

Lawson AE, Weser J. The rejection of nonscientific beliefs about life: effects of instruction and reasoning skills. J Res Sci Teach. 1990;27(6):589-606.

Lawson AE, Worsnop WA. Learning about evolution and rejecting a belief in special creation: effects of reflective reasoning skill, prior knowledge, prior belief and religious commitment. J Res Sci Teach. 1992;29:143-66.

Lloyd-Strovas JD, Bernal XE. A review of undergraduate evolution education in US universities: building a unifying framework. Evo Edu Outreach. 2012:5(3):453-65.

Mayr E. What makes biology unique?: considerations on the autonomy of a scientific discipline. Cambridge: Cambridge University Press; 2007.

Miller JD, Scott EC, Okamoto S. Public acceptance of evolution. Science. 2006;313(5788):765

Moore R, Brooks DC, Cotner S. The relation of high school biology courses and students' religious beliefs to college students' knowledge of evolution. Am Biol Teach. 2011;73(4):222-6.

Moore R, Decker M, Cotner SH. Chronology of the evolution-creationism controversy. Santa Barbara: ABC-CLIO; 2009.

Moore R, Cotner S. The creationist down the hall: does it matter when teachers teach creationism? Bioscience. 2009:59(5):429-35.

Nature Index. 2016. http://www.natureindex.com/annual-tables/2016/country/all. Accessed 21 Apr 2016

Nehm RH. Faith-based evolution education? Bioscience. 2006;56(8):638-9.

Paul $\mathrm{G}$. The chronic dependence of popular religiosity upon dysfunctional psychosociological conditions. Evol Psychol. 2009;7(3):398-441.

Paz-y-Miño GC, Espinosa A. Acceptance of evolution increases with student academic level: a comparison between a secular and a religious college. Evo Edu Outreach. 2009;2(4):655-75

PISA_Programme for International Student Assessment. Assessment and analytical framework: mathematics, reading, science, problem solving and financial literacy. OECD publishing. 2012. http://www.oecd.org/pisa/ keyfindings/PISA-2012-results-brazil.pdf. Accessed 23 Mar 2016.

R Core Team. R: a language and environment for statistical computing. Vienna: R Foundation for Statistical Computing. 2017. (http://www.R-project. org/). Accessed 10 Feb 2017.

Rees TJ. Is personal insecurity a cause of cross-national differences in the intensity of religious belief? J Rel Soc. 2009;11:1-24.

Rice JW, Olson JK, Colbert JT. University evolution education: the effect of evolution instruction on biology majors' content knowledge, attitude toward evolution, and theistic position. Evo Edu Outreach. 2011;4(1):137-44.

Rocha LB, Silva HM, Carvalho GS. The origin of man: biological sciences and pedagogy students' conceptions. J Teach Edu. 2016;5(1):185-90.

Scott EC. Evolution vs. creationism: An introduction. 2nd ed. Berkeley: University of California Press; 2009

Sherkat DE. Religion and scientific literacy in the United States. Soc Sci Quart. 2011;92(5):1134-50.

Sinclair A, Pendarvis MP, Baldwin B. The relationship between college zoology students' beliefs about evolutionary theory and religion. J Res Dev Edu. 1997:30(2):118-25.

Venables WN, Ripley BD. Modern Applied Statistics with S. New York: Springer; 2002

Wiles JR, Alters B. Effects of an educational experience incorporating an inventory of factors potentially influencing student acceptance of biological evolution. Int J Sci Educ. 2011;33(18):2559-85.

Zuur AF, leno EN, Walker NJ, Saveliev AA, Smith GM. Mixed effects models and extensions in ecology with R. New York: Springer; 2009. 